\title{
Copula-based modeling of earthen levee breach due to overtopping
}

\author{
Matteo Balistrocchi ${ }^{\mathrm{a}, *}$, Giovanni Moretti ${ }^{\mathrm{b}}$, Stefano Orlandini ${ }^{\mathrm{b}}$, Roberto Ranzi ${ }^{\mathrm{a}}$ \\ ${ }^{a}$ Department of Civil Environmental Architectural Engineering and Mathematics, University of Brescia, Brescia, Italy \\ ${ }^{\mathrm{b}}$ Department of Engineering Enzo Ferrari, University of Modena and Reggio Emilia, Modena, Italy
}

\section{A R T I C L E I N F O}

\section{Keywords:}

Bivariate statistics

Copula functions

Earthen levees

Failure probability

Overtopping breaching

Residual hazard

\begin{abstract}
A B S T R A C T
The level of protection offered by an earthen levee is typically described in terms of flood water level that the levee is capable of containing. If a larger flood occurs, floodwaters exceed the height of the levee and flow over its crest. As the water passes over the top, it may erode the levee, worsening the flooding and potentially causing a breach. In order to determine the annual probability that an earthen levee breaches due to overtopping, multiple flood characteristics such as peak flood water level, or related peak flow discharge, and flood duration need to be characterized statistically by using multivariate statistics. In this study, critical conditions for levee failure are described by using a Clayton copula relating peak flow discharge to flood duration. The obtained model is tested over a real river site located along the Panaro River, in northern Italy, where a 52-year time series of hourly flow discharge and a normal flow rating curve are available. The developed model makes it possible to delimitate the levee failure region within the population of flood events and to statistically describe earthen levee breach due to overtopping. Breach probability is found to be underestimated when the statistical association between peak flow discharge and flood duration is neglected. The proposed copula-based model is therefore important to support the design and construction of earthen levees, and to identify the actions needed to save lives and property when a flood exceeding the levee design limit occurs.
\end{abstract}

\section{Introduction}

In the last two decades there has been an increasing call for developing probabilistic methods devoted to the design and the safety verification of flood defense structures involved in flood risk control and mitigation. The main research focus in this field has progressively evolved from a structure-oriented approach, to the more comprehensive risk-based approach (USACE, 1996, 1999; Vrijling, 2001; Apel et al., 2006; Kellens et al., 2013; Schumann, 2017). In the structure-oriented approach, the procedure limits to assess the structure performances with respect to a hydraulic load, as referred to a design return period. This parameter measures the event severity and is utilized to define the socalled flood hazard. Thus, a defense structure is considered to be verified when it is able to completely control, with a prescribed degree of safety, a flood hydrograph associated with a sufficiently large return period. The risk-based approach, in addition to the flood hazard, accounts for damages to people, human health, private and public assets, cultural heritage and ecosystem services. Such damages are usually expressed in terms of exposure and vulnerability, so that the overall flood risk is given by the combination (EU, 2007; UNISDR, 2009), for instance the product (Varnes, 1984), of these three factors. In fact, flood management strategies have progressively left apart the purpose of an almost total control of flood events, in favor of a more realistic one, admitting that the flood risk can be attenuated, but not completely eliminated, thus leaving a residual risk to be estimated. This perspective change has become increasingly important as urbanization growths inside flood prone areas (ASCE, 2014). According to the levee paradox (Castellarin et al., 2009; Ludy and Kondolf, 2012), the flood risk may be higher after the construction or the strengthening of flood defense structures. This can be explained by the flood hazard perception lowering, that determines the anthropization sprawl into flood prone areas, where exposure and vulnerability increase appreciably (Wilby et al., 2008). In fact, an excessive rise of earthen levee height may cause flood damages due to failures to increase with respect to those occurring with a smaller levee height. For instance, this situation was actually experienced in New Orleans, where the disruptive consequences of hurricane Katrina made it evident that the result of a long-term pattern of flooding protection strategies decreased the impact of relatively frequent events, but increased the vulnerability to the extreme ones (Kates et al., 2006).

In a risk-based analysis, the derivation of reliable inundation maps plays a crucial role (EU, 2007), as they allow hydrologists and decision makers to define the inundation extent, related water stages and flow velocities, and to identify the exposed lives and properties, along with their vulnerability (Milanesi et al., 2015). In theory, all relevant

\footnotetext{
* Corresponding author.

E-mail address: matteo.balistrocchi@unibs.it (M. Balistrocchi).
} 
inundation scenarios should be taken into consideration, including those generated by the overload, the total failure or the partial failure of the flood defense system, and suitably associated with the hazard. This involves assessing the so-called residual risk, or the risk that remains in unmanaged form even when effective disaster risk reduction measures are in place (UNISDR, 2009). In this regard, studying the structural safety of earthen levees, whose failure is primarily, but not only, related to flood triggered breaching, is the first logical step. As highlighted by a broad literature after Apel et al. (2004), a complete risk-based analysis should investigate a chain consisting of the following steps: (i) assessment of the hydrological load, (ii) routing of the flood hydrograph along the river channel or through flood control reservoirs, (iii) detection of the most probable breach locations, (iv) generation of breach overflow hydrographs, (v) computation of the inundation maps, and (vi) estimate of the economic damage. In the past, studies exploited historical information (Han et al., 1998; Hesselink et al., 2003) or reasonable hypotheses (Aureli and Mignosa, 2004) to face the third step. Unfortunately, these approaches make it difficult to establish an appropriate statistical relationship between the flood event and the inundation scenario, and can feature great uncertainties.

From a theoretical point of view, a probabilistic approach provides the most suitable tool for detecting the potential breach locations, through the estimate of the levee failure probability, herein referred to as structural residual hazard. Dealing with earthen levees, the structural residual hazard must measure the probability that the levee crest is overtopped leading to a breach formation, or that alternative failure mechanisms occur. Indeed, as remarked by various authors (Vrijling, 2001; Ranzi et al., 2013; Orlandini et al., 2015; NCHRP, 2016), recurrent failure mechanisms triggered by floods are: internal erosion due to piping, bulk seepage or underseepage, external erosion due to waves or overtopping, foundation lateral sliding and saturation softening. The structural residual hazard is therefore the total probability of all these events. Further, a design hydraulic residual hazard can be defined in relation to the exceedance probability of the river conveyance capacity. This hazard is larger than the structural residual hazard strictly related to the overtopping failure mechanism, since not all the overflow events lead to a breach formation. The residual risk is the combination of the residual hazard, the exposure and the vulnerability (Varnes, 1984; UNISDR, 2009), so that a structural residual risk and a design hydraulic residual risk can be derived from these two hazard types. It should be noticed that, unlike the hazard, the design hydraulic residual risk is basically smaller than the structural residual risk associated only with the breach formation due to overtopping. In fact, when a breach occurs, a flooding volume far larger than that determined by the simple levee overtopping is expected. The flooded area consequently increases, along with the exposure.

The computational burden and the amount of data make it virtually impossible to perform levee failure analyses at a river watershed scale by means of detailed simulation models (e.g. Fread, 1988; Fiorentini and Orlandini, 2013). This issue is particularly sensitive for historical levee systems, whose geometrical and geotechnical properties are highly variable. Ultimately, for watershed planning purposes, practical expeditious methods incorporating parameter uncertainty represent the most feasible manner to face the assessment of levee failure probability (Camici et al., 2017). To this aim, levee fragility curves were proposed to estimate the probability of structural failure conditioned upon the flood load (Vorogushyn et al., 2009). Such curves are derived for single failure mechanisms, by means of deterministic transformation functions operating on a certain number of flood variables which, in most studies, are represented by the peak flow discharge, or the maximum water stage, and the flood duration. An indicator variable, summarizing the comparison between the levee resistance and the flood load, discriminates whether the levee is under a structural safety condition or under a structural failure condition. To account for the epistemic uncertainty, due to the limited knowledge of the geometrical and geotechnical properties contributing to the levee resistance, some parameters of the trans- formation functions are randomized according to Monte Carlo simulation techniques. Hence, fragility curves represent the percentage of assessed failure conditions with respect to the total number of simulation runs. The more fragile the levee is, the more abrupt the curve increasing trend with regard to the flood variables. For each failure mechanism of interest, a distinct fragility curve must be derived. Therefore, when multiple failure mechanisms are involved, specific fragility curves must be combined in order to describe the mutual dependence. Nonetheless, in our opinion, a better interpretation should be given to the aleatory uncertainty, which expresses the natural variability of the hydrologic loads.

Despite their popularity, it must be pointed out that fragility curves are affected by drawbacks, which derive from the lack of a comprehensive stochastic representation of the hydrologic load. In fact, all failure mechanisms triggered by floods depend on multiple characteristics of the hydrographs, mainly the peak flow discharge and the flood duration. Such variables always feature complex and non-negligible dependence structures, whose suitable modeling is a primary objective, even more than the epistemic uncertainty, in order to obtain reliable risk estimates. On the contrary, fragility curve derivations have been conducted by assuming flood variables to be independent (Apel et al., 2004), or by using arbitrarily set values for the flood durations (Michelazzo et al., 2018; Barbetta et al., 2017; Mazzoleni et al., 2017) to derive synthetic design hydrographs from flood reduction curves (Majone et al., 2003). Consequent drawbacks are: (i) owing to the arbitrary choices that it involves, the synthetic event approach is affected by a large uncertainty and leads to biased probability estimates (Adams and Howard, 1986), (ii) the flood hazard is actually measured in terms of univariate return period of the peak flow discharge, (iii) it was emphasized that conditional approaches lead to risk estimates statistically incomparable to those obtained by fully exploiting multivariate approaches which, in theory, provide the most straightforward and technically sound methodology to face multivariate problems.

Indeed, flood variables show to be related through concordant dependence structures, whose strengths vary from moderately strong to strong. Their natural variability was modeled by using joint distribution functions featuring upper tail dependence properties (Zhang and Singh, 2007; Karmakar and Simonovic, 2009; Requena et al., 2013), or lower tail dependence properties (Chowdhary et al., 2011; Balistrocchi et al., 2017) or both (Ganguli and Reddy, 2013). Moreover, the independence assumption basically leads to biased and potentially non conservative residual hazard estimates. For instance, Salvadori et al. (2015) found that the independent assumption leads to the underestimation of sea storm loads to breakwaters. In particular, the upper tail modeling has relevant consequences on the representation of the extreme events (Poulin et al., 2007; Balistrocchi and Bacchi, 2017), which are of uppermost interest for practical applications. In the existing literature, the residual hazard of earthen levee breach due to overtopping has never been estimated by using bivariate statistical analyses involving flood peak and duration.

A research gap remains therefore to be filled, in order to obtain a reliable representation of the multivariate nature of the floods and of the related evaluation of failure probability of earthen levees. Copula functions are a powerful tool for investigating the dependence structure of flood variable samples and for developing their joint distribution functions (Joe, 1997; Nelsen, 2006; Favre et al., 2004; Salvadori and De Michele, 2004; Grimaldi and Serinaldi, 2006; Salvadori and De Michele 2006; Dupuis, 2007). This approach bears two main advantages: (i) it makes the assessments of the marginals independent of the dependence structure, so that probabilistic functions belonging to different families can be implemented in the joint distribution function, and (ii) due to the equivalence of the computed probability in the natural variable domain and in the probability domain, estimates can be conducted in the latter one by operating on finite regions; this property arises from the derived distribution theory (Eagleson, 1972), since uniform variables are derived through the probability integral transform (Angus, 1994). 
Unfortunately, there is no unique definition of return period based on multivariate statistics. Owing to the absence of a total order relationship in multivariate populations, various operative definitions can be formulated, leading to statistically different estimates. As summarized by Salvadori et al. (2016), various criteria were suggested to separate the event population into the sub-critical region and the super-critical region: OR, AND, Kendall, Survival-Kendall and structural-based. It is recognized that the structural-based criterion however provides a technically sound strategy to deal with practical engineering problems, since specific estimate methods can be developed by using the derived distribution theory (Eagleson, 1972), aiming at best suiting the dynamics of the failure mechanism of interest (Requena et al., 2013; Volpi and Fiori, 2014; Serinaldi, 2015).

Thus, a structural-based criterion is used in the present study to estimate the structural residual hazard related to earthen levees breaching due to overtopping. Indeed, overtopping has often been acknowledged as one of the most common causes of levee breaching (see Vorogushyn et al., 2009, and references therein). This probability must be regarded as a component of the total structural residual hazard, which should also incorporate the contributions of all the other significant failure mechanisms. More than the conditional ones, this approach is capable to straightforwardly and effectively investigate the multivariate nature of the breaching due to overtopping, and delineates a general strategy to investigate other failure mechanisms. The aleatory uncertainty is represented by a bivariate distribution function of the peak flow discharge and the flood duration. This distribution is constructed by using the Clayton copula. A simplified transformation functions is used to separate the bivariate population of flood variables into safety and failure regions, whose parameters are randomized, according to Monte Carlo simulation techniques. Therefore, the final outcome of the presented method consists of the average structural residual hazard of levee breaching and its uncertainty.

The estimate methodology herein developed is then applied to a real site located along the Panaro River in northern Italy, to illustrate its practical applicability. The levee is located immediately upstream of the Bomporto river gauge station, which has recorded a historical series of hourly flow discharges between 1923 and 1983. Below, key issues regarding the construction of the flood event distribution based on the copula approach are firstly reported (Section 2). Then, the modeling technique of levee failure mechanism including the estimate of the residual hazard is fully described (Section 3). The case study and the related epistemic uncertainty modeling are reported in Section 6. The full dataset needed to reproduce the results reported in the present study can be obtained as indicated in Acknowledgment and data section.

\section{Bivariate probabilistic flood modeling}

In this study, the bivariate modeling of flood events is developed by using a bivariate joint distribution function (JDF) of the peak flow discharge and the flood duration, which can be considered mutually dependent random variables, whose dependence can be verified by statistical tests. These variables affect the flood volume and can therefore be used to shape suitable flood hydrographs. According to the Sklar theorem (Sklar, 1959), the JDF $P_{Q p D}$ can be written in the terms of Eq. (1), where $P_{Q p}$ and $P_{D}$ are respectively the marginal cumulative distribution functions (CDFs) of the peak flow discharge $q_{p}$ and the flood duration $d$, while $C_{\theta}$ is the copula function.

$P_{Q p D}\left(q_{p}, d\right)=C_{\theta}\left[P_{Q p}\left(q_{p}\right), P_{D}(d)\right]$

In a bivariate case, the copula function $C_{\theta}$ is defined with respect to a couple of uniformly distributed random variables $u$ and $v$, varying in the unitary square $[0,1]^{2}$, which can be derive from the corresponding flood variables through the probability integral transforms shown in Eq. (2). Owing to this definition, $C_{\theta}$ is independent of marginal
CDFs and therefore characterizes only the bivariate dependence structure (Salvadori et al., 2007).

$C_{\theta}(u, v):[0,1]^{2} \rightarrow[0,1] \quad$ with $\quad u=P_{Q p}\left(q_{p}\right)$ and $v=P_{D}(d)$

Thus, the flood variable JDF is decomposed in three functions, so that its pieces can be investigated separately from the others and in a more effective manner. Essential features of bivariate probabilistic modeling are discussed in the sub-sections reported below, while statistical analyses needed to verify the above mentioned assumptions are briefly reported in Section 5.1.

\subsection{Independent flood sampling}

To assess JDF (1), independent flood events must be sampled from the continuous time series. In this study, the peak over threshold criterion was preferred to the annual maximum statistics, because of its well-known advantages in terms of sample representativeness (Todorovic, 1978; Lang et al., 1999). In addition to the threshold discharge $q_{t}$, a minimum interevent period between subsequent floods is implemented (Yevjevich, 1967), to achieve the independence prerequisite of random occurrences (Brunner et al., 2017; Balistrocchi et al., 2017). The values of such sampling parameters need to be constrained to yield realistic description of the physics governing the system forced by flood events. In general, the threshold parameter needs to yield hydrologic events significant to the system behavior, whereas the minimum interevent period needs to be long enough to ensure that the system initial condition is restored, when the subsequent event onsets. Once independent flood events are detected, a bivariate sample of peak flow discharges $\hat{q}_{p i}$ and flood durations $\hat{d}_{i}$ is derived, along with the average annual number of flood events $\omega$. The first observation is extracted from the total observed flow discharge and preserves the contribution of the flow discharge below the threshold. The second observation is computed by linearly interpolating the flow discharge variation when the hydrograph crosses the threshold discharge.

\subsection{Dependence structure modeling}

The dependence structure relating the peak flow discharge and the flood duration is herein modeled by means of the Clayton copula, which demonstrated satisfactory fitting capabilities (Chowdhary et al., 2011). Table 1 supplies the most general expression of the bivariate members of this family, whose dependence parameter $\theta$ is strictly positive for concordant associations, negative for discordant associations and null in the limiting case of independence (Salvadori et al., 2007). The relationship between the dependence parameter and the Kendall rank correlation coefficient $\tau_{K}$ is also reported in Table 1 . The dependence structure expressed by the Clayton copula features a minor event association stronger than the overall dependence. This property is quantified by a lower tail dependence coefficient $\lambda_{L}$, whose theoretical value is related to the dependence parameter $\theta$ by the expression reported in Table 1 . Conversely, the upper tail dependence coefficient $\lambda_{U}$ is null, so that the extreme event association is negligible. Note that the tail dependence herein mentioned refers to theoretical model, independently of the practical difficulties inherent its assessment (Serinadi et al., 2015).

Although the Clayton copula provides a thoroughly satisfactory modeling of the empirical dependence structure, alternative copula functions providing different tails modeling, namely the $t$-Student copula and the Gumbel copula, were taken into consideration. This is intended to merely quantify the effect of misinterpreting the upper and lower tail dependences on the residual hazard estimate. The $t$-Student copula is an elliptic copula that features symmetric tail dependences, as $\lambda_{L}$ and $\lambda_{U}$ are equal. These coefficients increase with the dependence parameter $\theta$ and decrease with the degrees of freedom $v$, so that for the limiting case of the Gaussian copula they are null. Differently, in the Gumbel copula the lower tail dependence is null, while the upper tail dependence coefficient exists and increases with $\theta$. Further, the independence copula, or $\Pi$ 
Table 1

Analyzed copula functions.

\begin{tabular}{lllll}
\hline Copula & Function & Parameters & $\lambda_{l}(-)$ & $\lambda_{u}(-)$ \\
\hline Clayton & $C_{\theta}(u, v)=\left[\max \left\{\left(u^{-\theta}+v^{-\theta}-1\right), 0\right\}\right]^{-1 / \theta}$ & $\theta=2 \tau_{k} /\left(1-\tau_{k}\right)$ & $2^{-1 / \theta}$ & 0 \\
Student & $C_{\theta, v}(u, v)=\int_{-\infty}^{t_{v}^{-1}(u)} \int_{-\infty}^{t_{v}^{-1}(v)} \frac{1}{2 \pi \sqrt{1-\theta^{2}}}\left(1+\frac{s^{2}-2 \theta s t+t^{2}}{v\left(1-\theta^{2}\right)}\right)^{-\frac{(u+2)}{2}} d s d t$ & $\theta=\sin \left(\frac{\pi \tau_{k}}{2}\right) ; v$ & $2 t_{v+1}\left(-\frac{\sqrt{v+1} \sqrt{1-\theta}}{\sqrt{1+\theta}}\right)$ & $2 t_{v+1}\left(-\frac{\sqrt{v+1} \sqrt{1-\theta}}{\sqrt{1+\theta}}\right)$ \\
Gumbel & $C_{\theta}(u, v)=\exp \left\{-\left[(-\ln u)^{\theta}+(-\ln v)^{\theta}\right]^{1 / \theta}\right\}$ & $\theta=1 /\left(1-\tau_{k}\right)$ & 0 & $2-2^{1 / \theta}$ \\
Independence & $C(u, v)=u v$ & - & 0 & 0 \\
\hline
\end{tabular}

$\theta$ dependence parameter $(-), v$ degrees of freedom $(-), t_{v} t$-Student univariate distribution with $v$ degrees of freedom.

copula, was also considered to evaluate the consequences of completely neglecting the dependence structure. Functions and characteristics of these copulas are listed in Table 1.

\subsection{Marginal distribution modeling}

To represent the marginal variability, CDFs conventionally employed in statistical hydrology were found to be suitable choices. More precisely, satisfactory fits to data were obtained both for the peak flow discharge and for the flood duration through the Weibull distribution function. With respect to other more popular choices in flood frequency analysis, the Weibull model actually yielded the best ability to fit the upper tail of the peak flow discharge sample and the lower tail of the flood duration sample. Their expressions are reported in the following equations, where $\kappa_{q}$ and $\zeta_{q}$ are the shape and scale parameters of the flow discharge distribution (3), while $\kappa_{d}$ and $\zeta_{d}$ are the corresponding parameters of the flood duration distribution (4). In Eq. (3) the discharge threshold $q_{t}$ is implemented as the distribution lower limit, arising from the flood event sampling procedure.

$$
\begin{aligned}
& P_{Q p}\left(q_{p}\right)= \begin{cases}1-\exp \left[-\left(\frac{q_{p}-q_{t}}{\zeta_{q}}\right)^{\kappa_{q}}\right] & \text { for } q_{p}>q_{t} \\
0 & \text { elsewhere }\end{cases} \\
& P_{D}(d)= \begin{cases}1-\exp \left[-\left(\frac{d}{\zeta_{d}}\right)^{\kappa_{d}}\right] & \text { for } d>0 \\
0 & \text { elsewhere }\end{cases}
\end{aligned}
$$

\section{Breaching modeling}

In general, the estimate of structural failure probabilities can be conducted by means of a limit state function of the type indicated in Eq. (5), expressing the difference $Z$ between a structure resistance factor $R$ and an external load factor $L$ (Apel et al., 2004; Vorogushyn et al., 2009). This is a stochastic function in which both the aleatory uncertainty and the epistemic uncertainty can be accounted for. The first kind of uncertainty is incorporated by means of the JDF featuring the load variables. Conversely, the second kind of uncertainty is incorporated by randomizing the function parameters, according to Monte Carlo techniques.

$Z=R-L$

The sign assumed by the limit state function (5) discriminates whether the structure is under a safe load condition or not. Therefore, only load combinations yielding negative values are assumed to trigger the failure mechanism. The resistance factor and the load factor in Eq. (5) must be specified for each failure mechanism of interest. The method utilized to define $R$ and $L$ factors for breaching due to overtopping is discussed below.

\subsection{Hydraulic load}

The load factors $L$ forcing the levee are herein derived from synthetic flood events, defined with regard to the same random variables used to construct the JDF given in Eq. (1). Indeed, according to Ranzi (2005), a complete hydrograph can suitably be defined by using Eq. (6), which is developed in analogy with the gamma probability density function to suit the selected values of peak flow discharge $q_{p}$ and flood duration $d$. Hence, the instantaneous discharge $q$ depends on the time $t$, through a time scale parameter $k$, affecting the flood volume, and a shape parameter $\alpha$, affecting the time to peak.

$q(t)=\frac{q_{p}}{\exp [-(\alpha-1)](\alpha-1)^{\alpha-1}}\left(\frac{t}{k}\right)^{\alpha-1} \exp \left(-\frac{t}{k}\right)$

While the hydrograph dependence on the peak flow discharge $q_{p}$ is explicit, the flood duration $d$ indirectly determines the time scale constant $k$, as these variables are related as shown in Eq. (7), where $\Gamma($.$) is$ the complete gamma function. The duration of this kind of hydrograph is theoretically infinite, but a finite duration can be established with reference to an equivalent triangular hydrograph, whose volume and peak equal those of the gamma hydrograph. Indeed, from a practical point of view, the recession limb can be considered completely depleted in the time period following the duration $d$.

$k=\frac{\exp [-(\alpha-1)](\alpha-1)^{\alpha-2}}{2 \Gamma(\alpha)} d$

As suggested by Apel et al. (2009), the limit state for stability before breaching due to overtopping is given by Eq. (5), which compares the erosional stress due to the overflow discharge and the resistance provided by the turf covering the levee inner talus. In this equation, the load factor is given by a specific flow discharge, which is related to the maximum overflow discharge overtopping the levee crest. In an expeditious procedure, the load factor is estimated to be the maximum excess flow discharge with respect to an overflow threshold discharge $q_{o}$, derived for the river section through the normal flow rating curve. Hence, given the peak flow discharge $q_{p}$ of the synthetic hydrograph, the specific discharge $q_{L}\left(\mathrm{~m}^{2} / \mathrm{s}\right)$, playing the role of load factor $L$, is simply assessed by Eq. (8), where a suitable overflow width $W_{o}(\mathrm{~m})$ must however be chosen. In this formulation, the overflow process is assumed to be identical for both sides of the river system, as appropriated when the levee crest elevations and discharge coefficients are the same.

$q_{L}=\frac{1}{2} \frac{q_{p}-q_{o}}{W_{o}}$

\subsection{Levee resistance factor}

The resistance factor can be estimated by using the formulation proposed by Vrijling (2000) and based on experimental analyses conducted by Hewett et al. (1987). A critical velocity $v_{c}(\mathrm{~m} / \mathrm{s})$ is thus evaluated with respect to the overflow duration $d_{o}(\mathrm{~h})$ and a dimensionless parameter $f_{g}$ measuring the erosion resistance capacity of the inner talus turf, as shown in Eq. (9).

$v_{c}=\frac{\left[3.9117+1.5\left(f_{g}-1\right)\right]}{1+\left[0.8575-0.45\left(f_{g}-1\right)\right] \log _{10} d_{o}}$

The overflow duration $d_{o}$ can directly be derived from the synthetic flood hydrograph, as the period in which the actual flow discharge $q$ exceeds the threshold overflow discharge $q_{o}$. The parameter $f_{g}$ depends on the turf type and quality condition. Parameter $f_{g}$ varies from 0.5 for poor turf condition to 1.5 for optimal turf conditions, being 1.0 representative of the average turf condition. However, when filled mats are used to protect the levee, this parameter can be set equal to 2 . The resistance 
factor $R$ is thus set equal to the critical specific discharge $q_{R}\left(\mathrm{~m}^{2} / \mathrm{s}\right)$ by Eq. (10), as a function of the critical velocity $v_{c}$, the Gauckler-Strickler conductance coefficient $k_{s}\left(\mathrm{~m}^{1 / 3} / \mathrm{s}\right)$ and inclination angle $\beta$ of the inner talus.

$$
q_{R}=\frac{v_{c}^{2.50} k_{s}^{-0.25}}{125 \tan \beta^{0.75}}
$$

Following this criterion, the levee breaches when $Z=q_{R}-q_{L}<0$, depending on both the flood duration $d$, which rules the critical velocity for the talus stability, and the peak flow discharge $q_{p}$, which rules the actual overflow discharge.

\subsection{Residual hazard estimate}

With respect to the limit state function $Z$, the population of floods is split in two dichotomous regions: a safety region, for positive values of $Z$, and a failure region, for negative values of $Z$. In a bivariate case, such regions are separated by a curve indicating the exact balance between the resistance factor and the load factor. By definition, the structural residual hazard is the integral of the probability density function over the failure region. This integral can be computed in the probability space by using the copula approach, that is, by transforming the semiinfinite regions into definite regions, lying within the unitary square $[0,1]^{2}$. In this application, the failure region $\Lambda_{s}$ can be delimitated as indicated in Eq. (11), where marginal CDFs (3) and (4) need to be inverted.

$\Lambda_{s}=\left\{(u, v) \in[0,1]^{2} \mid Z\left[P_{Q p}^{-1}(u), P_{D}^{-1}(v)\right]<0\right\}$

The probability of occurrence of an individual flood event leading to a breach due to overtopping is thus computed by integrating the copula density function $c_{\theta}=\partial^{2} C_{\theta} /(\partial u \partial v)$ over the failure region $\Lambda_{s}$. A straightforward formulation based on the well-established definition of longterm failure probability (Chow et al., 1988), traditionally referred to as inherent or natural hydrologic risk (USACE, 1996; Akan and Houghtalen, 2003), appears to be appealing and technically sound. Hence, given the annual structural residual hazard related to breaching due to overtopping, obtained by multiplying the event probability for the average annual number of events $\omega$, the long-term structural residual hazard $H_{N}$ is estimated by Eq. (12), as the probability that a load $q_{L}$ exceeding the system resistance capacity $q_{R}$ occurs in $N$ years. This time interval was firstly defined by Thomas (1948) as planning period.

$H_{N}=1-\left(1-\omega \int_{\Lambda_{s}} c_{\theta} d u d v\right)^{N}$

The design hydraulic residual hazard, routinely adopted in hydrology to assess the failure probability, can be computed according to this methodology as well. In this case, a univariate approach can be followed, as only the exceedance probability of the threshold flow discharge is involved in the failure mechanism. Hence, with regard to the bivariate space herein utilized, the failure region $\Lambda_{d}$ can be delimitated as shown in Eq. (13). The long-term design hydraulic residual hazard $H_{N}{ }_{N}$ is finally given by Eq. (14).

$\Lambda_{d}=\left\{(u, v) \in[0,1]^{2} \mid P_{Q p}^{-1}(u) \geq q_{o}\right\}$

$H_{N}^{\prime}=1-\left\{1-\omega\left[1-P_{Q p}\left(q_{o}\right)\right]\right\}^{N}$

\section{Case study}

The estimate method of the structural residual hazard herein developed was applied to a real-world levee located along the left hand side bank of the Panaro River, the last right hand side bank tributary of the Po River (northern Italy). This study site is located $1 \mathrm{~km}$ upstream of the Bomporto gauge station. As can be seen in Fig. 1a, this river section lies in the Padan Plain and drains nearly the total watershed area.
The river flow was monitored from 1923 to 1983 by the Italian hydrographic agency (Servizio Idrografico Italiano, SII), providing an almost complete 52-year series of hourly flow discharges. This series is representative of riverflows occurring prior to the construction of the Sant'Anna flood control reservoir, a $24 \times 10^{6} \mathrm{~m}^{3}$ on-line storage capacity located twenty kilometers upstream of the Bomporto river section. However, the aim of the application reported in the present study is not to provide a site-specific assessment of earthen levee safety, but rather to illustrate a general methodology that can be applied to any earthen levee system, independently of presence or not of a flood control reservoir. The availability of direct flow observations makes it possible to strictly focus on the main objective of this study, leaving apart the uncertainties related to the other components of the risk analysis chain.

\subsection{Site description}

The Panaro River originates from the northern hillside of the Apennines and, after a course $130 \mathrm{~km}$ long, reaches the Po River next to Ficarolo, where the first documented bank breach of the Po River occurred in the XII century. The total watershed area drained at the river outlet amounts to $1780 \mathrm{~km}^{2}$. The Bomporto gauge station, shown in Fig. 1b, belongs to a plain river reach and drains a catchment displaying an area of $1036 \mathrm{~km}^{2}$, a main stream length of $106 \mathrm{~km}$, an average elevation drop of $640 \mathrm{~m}$, and a time of concentration $t_{c}$ of about $14 \mathrm{~h}$. In this river section the flow discharge regime is normally due to rainfall events, but important snow melt contributions can be observed in winter and in spring. In the Apennine side of Po River drainage basin, the rainfall regime has two maxima: the main one in autumn and the secondary one in spring. Summer and winter are typically dry seasons. In late spring and in summer, rainfalls are usually generated by convective storms with limited spatial extensions, featuring high intensities, short durations, and relatively small volumes and limited spatial extensions, with respect to stratiform precipitations occurring in autumn. Stratiform events feature longer durations, lower intensities, and larger rainfall volumes. In terms of flood severity, rainy seasons represent the most critical periods: the largest flood event occurs basically in autumn and a secondary flood event occurs in spring. Large flood events due to rainfall on snow have however been observed in winter. The short time of concentration contributes to make such flood events particularly intense, so that peak flow discharges up to $925 \mathrm{~m}^{3}$ /s were measured during the observation period. No glacier is present to sustain the flow discharge during summer, so that low baseflow is often observed from the end of July and the beginning of September.

The riverbed of the Panaro River plain reach was recently surveyed by a high-precision LIDAR scan, displaying elevation error less than $15 \mathrm{~cm}$ and plain error less than $30 \mathrm{~cm}$, that was used to generate a $1-\mathrm{m}$ digital terrain model. A detailed and reliable geometrical characterization of the analyzed levee was then extracted from the available highresolution digital elevation model. As can be seen in Fig. 1c, a nearly symmetric river section, characterized by a shallow channel bounded by large banks is depicted. The levee crests rise up to $30.5 \mathrm{~m}$ a.s.l. on both sides, delimitating a cross section area of about $610 \mathrm{~m}^{2}$. In the last decades, due to a general reduction of the resources devoted to river bed maintenance, intense brush and bush covers have grown up on the banks and even in the channel, so that extensive sediment deposits have developed. However, in the past, when the series utilized in this study was observed by SII, maintenance were routinely conducted by removing vegetation and sediments. The overall conveyance capacity has significantly decreased since the early ' 80 s, as evidenced by the comparison of the normal flow rating curve estimated by the regional agency currently in charge of the hydro-meteorological monitoring of the Panaro River watershed (ARPAE, 2016), and that defined in the SII hydrologic annals (SII, 1940). To ensure consistency with the available time series, the hydraulic conductivity parameters were set with regard to the normal flow rating curve assessed by SII under the former condition and 

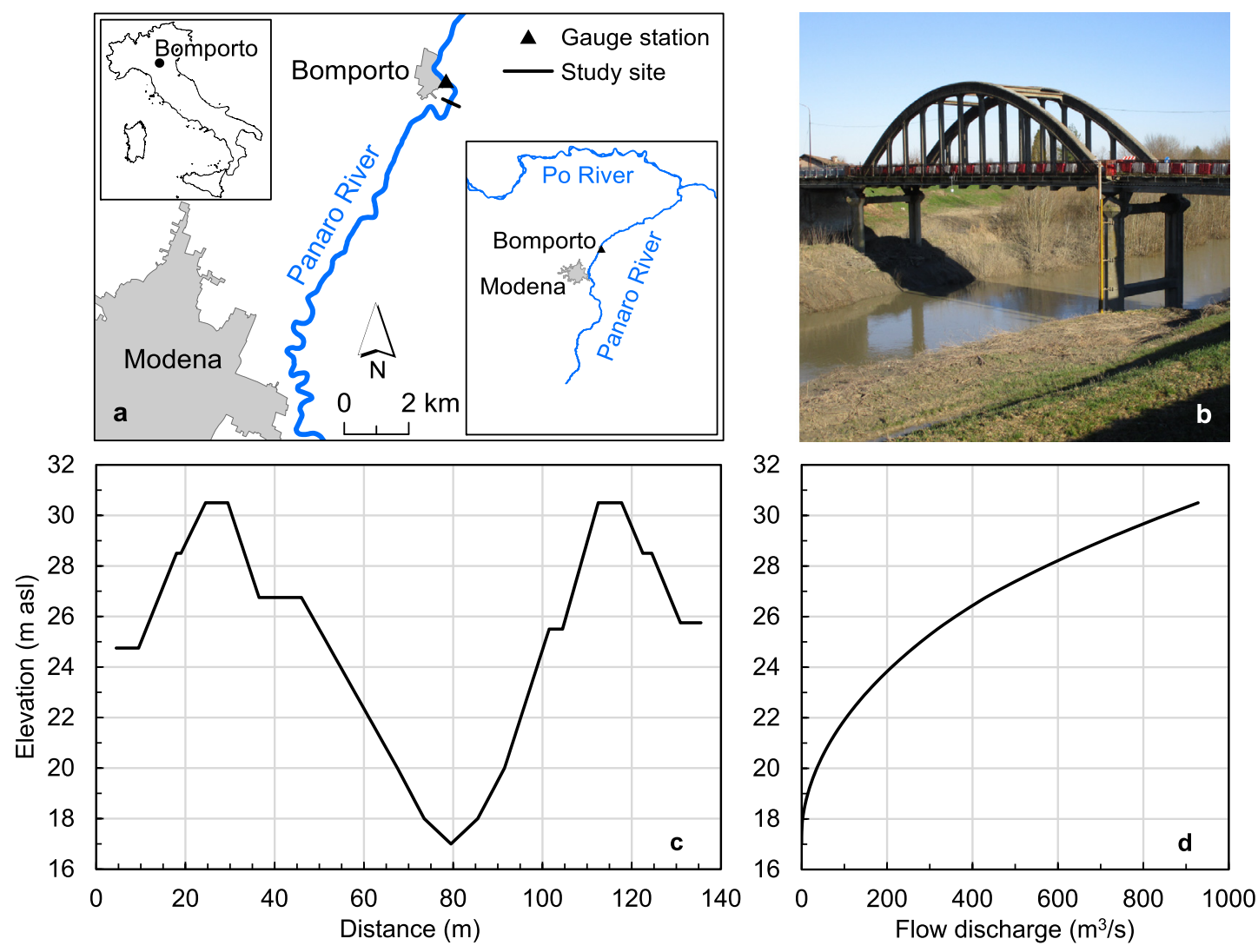

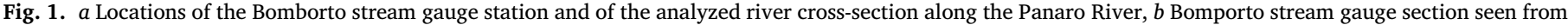
downstream in winter, $c$ river section outline and $d$ corresponding normal flow rating curve.

for this reason the time series was limited to the period 1923-83. It is stresses here that the case study reported in this paper is not aimed at providing a site-specific test of the present condition of the Panaro River, but rather to test a new methodology in a technically sound manner. A quite straight river bed, featuring fine grain sediments in the channel and banks mainly covered by grass and moderate-light brush were assumed to represent the considered study site. Gauckler-Strickler conductance coefficients for the channel $k_{s c}$ and for the banks $k_{s b}$ have been set equal to $30 \mathrm{~m}^{1 / 3} / \mathrm{s}$ and $13 \mathrm{~m}^{1 / 3} / \mathrm{s}$, respectively. The resulting normal flow rating curve is plotted in Fig. 1d. The overflow threshold discharge $q_{o}$ is estimated to be $930 \mathrm{~m}^{3} / \mathrm{s}$.

\subsection{Epistemic uncertainty modeling}

Bearing in mind the reliability of the topographic survey, the parameter set taken into consideration for the epistemic uncertainty modeling is essentially selected to represent the hydraulic and hydrologic uncertainties. Such parameters are listed below, in order of importance with respect to the estimate procedure sensitivity, along with the characteristics of the corresponding CDFs implemented in the Monte Carlo simulations.

- Overflow threshold discharge $q_{o}$ : this variability was accounted for by using the normal rating curve, since the most relevant uncertainties arise from the estimate of the Gauckler-Strickler conductance coefficients for channel and banks; their mean values were selected to reproduce the value of $930 \mathrm{~m}^{3} / \mathrm{s}$ at the elevation of $30.5 \mathrm{~m}$ a.s.l.; these mean values can reasonably vary within $\pm 10 \%$ with respect to their averages, and their standard deviations can be set equal to $1 / 6$ of this range; thus, the standard deviation of the overflow threshold discharge is estimated at $27.3 \mathrm{~m}^{3} / \mathrm{s}$, by applying the properties of the dependent random variables; the overflow threshold discharge was then modeled by using a log-normal distribution.

- Overflow width $W_{o}$ : for practical application purposes, the overflow width can be set equal to the breach width; according to historical breaches data, gathered in the Po River valley, the variability of such widths can be represented by a log-normal distribution having mean of $94 \mathrm{~m}$ and standard deviation of $21.7 \mathrm{~m}$ (Mazzoleni et al., 2014).

- Turf resistance factor $f_{g}$ : a triangular distribution can be used to represent the uncertainty related to the erosion resistance offered by common grass covers (Mazzoleni et al., 2017); herein, the maximum range of variability $0.5-1.5$ is used (Apel et al., 2009) while the distribution mode is located in the range upper extreme; this choice is justified by considering that most of the floods occur in spring and autumn, when the turf condition is good due to the abundant precipitation, while the probability of occurrence of relevant floods in summer, the dry and warm season, is very low.

- Gauckler-Strickler conductance coefficient of the inner talus turf $k_{s}$ : the average value of the roughness coefficient of a grass cover with light brush can reasonably be set equal to $20 \mathrm{~m}^{1 / 3} / \mathrm{s}$; by assuming a variability range of $\pm 10 \%$ with respect to this mean, the standard deviation can be set at about $0.7 \mathrm{~m}^{1 / 3} / \mathrm{s}$, that is $1 / 6$ of the variability range; a log-normal distribution was adopted in this case as made for $q_{o}$.

- Hydrograph shape parameter $\alpha$ : to suitably approximate the flood hydrographs observed in the Panaro River, shape parameters can be chosen between 2 and 3 (Ranzi, 2005; Balistrocchi et al., 2018): the more anticipated the peak flow discharge, the smaller the shape parameter is; this parameter can be assumed to vary uniformly inside the selected range. 


\section{Results and discussion}

The sampling of independent flood events from the continuous flow discharge series was conducted by using a threshold flow discharge $q_{t}$ equal to $240 \mathrm{~m}^{3} / \mathrm{s}$ and a minimum interevent period equal to $24 \mathrm{~h}$. The first value was chosen in accordance with the normal flow rating curve reported in Fig. 1d, in order to obtain flood events that actually overflow the low flow banks and appreciably affect the considered levee. The second value was set with regard to the watershed time of concentration, which was estimated to be about $14 \mathrm{~h}$. The occurrence of multiple peak floods affects the resistance factor $R$, which decreases with the flood duration. Thus, a period separating the end of the recession limb and the onset of the rising limb of the successive peak that is larger than the time of concentration can be considered suitable for the initial condition of the inner turf to be restored. The first outcome for this parameterization of the flood event sampling procedure is the derivation of an average annual number of independent flood events $\omega$, which was found to be equal to 2.27 . This is a small value, supporting the independence hypothesis on flood occurrence. Moreover, $\omega$ is consistent with the above discussed experience on the flood regime in the Po River right bank tributaries. A strong concordant association is detected between the peak flow discharges and the flood durations, as the Kendall coefficient is estimated to be 0.72 ( $p$-value testing independence $<0.1 \%$ ).

\subsection{Joint distribution function assessment}

In this application, the moment-like method was adopted to fit the mono parametric copulas listed in Table 1 to sample data, since it is computationally more efficient and yielded estimates very similar to those achieved by the pseudo-likelihood method; this last method was exploited only for the bi parametric $t$-Student copula (Genest and Favre, 2007). Table 2 summarizes the estimated dependence parameters along with the $\log$-pseudo-likelihood values $L_{h}$, while visual fitting evaluations are provided in the supplementary material. As can be seen, the Clayton copula provides the highest likelihood, while the Gumbel copula the lowest one. The evaluation of the goodness-of-fit was conducted by the statistical test proposed by Genest et al. (2009). Thus, the adaptation of the theoretical copula to its empirical counterpart was measured by the Cramer-Von-Mises criterion $S_{n}$, as the sum of the squared residuals. By using a parametric bootstrap procedure, the null hypothesis that the underlying copula is the selected one can be tested, obtaining an approximated $p$-value. As the sample size $n$ is slightly greater than $10^{2}$, a number of simulation runs equal to $10^{5}$ was considered to be sufficient to obtain accurate $p$-value estimates. Details on pseudo-observation generation through Monte Carlo simulation techniques, based on conditional approaches improved by using the probability integral transform can be found in Mai and Scherer (2012) and Hofert et al. (2018). In particular, $p$-values are strongly affected by the latter step. This is a computationally intensive procedure, whose burden is however significantly decreased by using the moment-like method to assess the theoretical copulas. The null hypothesis of independence can definitely be rejected, evidencing the significance of the concordance between flood variables. All the other copulas yield very low $S_{n}$ values, even if the goodness-of-fit shows a progressive detriment when the lower tail dependence is disregarded. The $p$-value estimates indicate that the Clayton copula cannot be rejected with respect to the $10 \%$ significance, while the others can.

Table 2

Calibration parameters, log-pseudo-likelihood Cramer-Von Mises statistics and $p$-values of tested copula functions $\left(10^{5}\right.$ simulation runs).

\begin{tabular}{lllll}
\hline Copula & Parameter & $L_{h}$ & $S_{n}$ & $p$-value (\%) \\
\hline Clayton & $\theta=5.15$ & 101.8 & 0.0155 & 33.9 \\
Student & $\theta=0.89, v=3.12$ & 91.4 & 0.0287 & 2.6 \\
Gumbel & $\theta=3.57$ & 66.4 & 0.0393 & 0.2 \\
Independence & - & 0 & 1.8920 & $<0.1$ \\
\hline
\end{tabular}
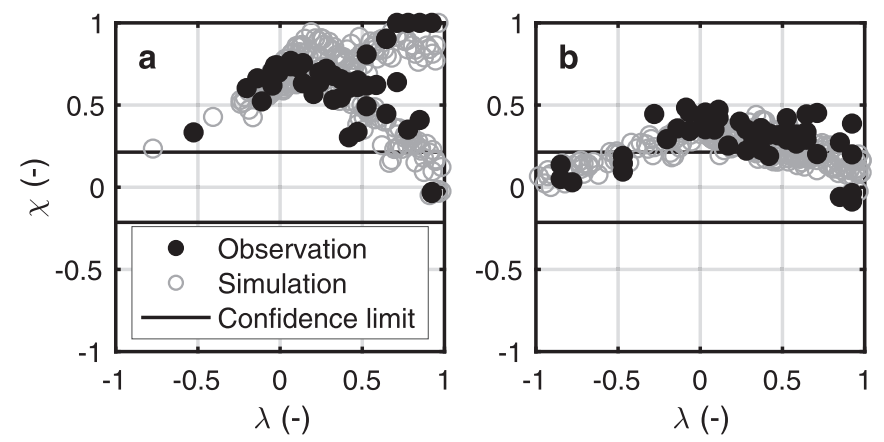

Fig. 2. Comparison of $\chi$-plots of the peak flow discharge and the flood duration couple derived for the observed sample and for a five hundred event sample simulated by using the assessed Clayton copula: $a$ lower tail and $b$ upper tail $(\chi$ departure from independence, $\lambda$ departure from bivariate median, confidence limits for independence plotted for $10 \%$ significance).

Consistently with the $\log$-pseudo-likelihood $L_{h}$ estimates, the smallest $S_{n}$ value is displayed by the Clayton copula, the largest $S_{n}$ value by the Gumbel copula, while the $t$-Student copula shows an intermediate result.

In addition to the overall goodness-of-fit evaluation provided by test statistics, a deeper insight into the tails behavior was accomplished by means of the $\chi$-plots (Fisher and Switzer, 1985). Such data visual explorations should be preferred to empirical tail coefficient estimators, since these estimates are presently affected by several drawbacks (Serinaldi et al., 2015), so that their quantification is a nontrivial task. A $\chi$-plot consists in a scatterplot of the departure from bivariate independence $\chi$ versus the distance from bivariate median $\lambda$. As suggested by Abberger (2005), $\chi$-plots can be exploited to investigate the tails behavior, when data subsets belonging to the lower-left quadrant (lower tail) and the upper-right quadrant (upper tail) with respect to the bivariate median are considered. The obtained $\chi$-plots are illustrated in Fig. 2, where the confidence limits testing independence are plotted for $10 \%$ significance according to Fisher and Switzer (2001). The lower tail is investigated in Fig. $2 \mathrm{a}$ : the $\chi$-plot reveals that the tail independence hypothesis can largely be rejected, as most of the occurrences lie out of the confidence limits. In addition, some occurrences show $\chi$ values up to one, evidencing a strong lower tail dependence. On the contrary, the $\chi$-plot reported in Fig. 2b shows that the upper tail dependence is negligible, since a greater number of occurrences lies within the confidence boundary and $\chi$ values are always less than 0.5 . Such outcomes reveal that a theoretical copula featuring lower tail dependence but not upper tail dependence should be preferred to other functions for suiting the pseudo-observation sample, and further support the choice of the Clayton copula as the most suitable solution.

To complete the JDF in accordance with Eq. (1), marginal distributions were fitted to the univariate samples by the maximum likelihood method, yielding these parameter estimates: $\kappa_{q}=0.85$, $\zeta_{q}=109.19 \mathrm{~m}^{3} / \mathrm{s}, \kappa_{d}=1.30, \zeta_{d}=18.54 \mathrm{~h}$. It can be noticed that the shape parameter of the peak flow discharge marginal is less than one, while that of the flood duration marginal is greater than one. This denotes different probability density functions for the marginal variables. In the first case, the function is monotonically decreasing from the lower limit, where a vertical asymptote is present. In the second case, the function features a finite maximum, corresponding to a mode greater than the lower limit. Confidence boundary tests for $10 \%$ significance are illustrated in Fig. 3, to show the goodness-of-fit of the selected CDFs. In both cases, since no occurrence lies outside the confidence limits, the null hypothesis cannot be rejected. A particular emphasis is given to the upper tail, to highlight the capability of the Weibull distributions to represent the characteristics of extreme flood events. Finally, the KolmogorovSmirnov test and the Anderson-Darling test strengthen the suitability of the selected Weibull distributions, see for details D'Agostino and Stephens (1986) and Kottegoda and Rosso (2008) and references therein 

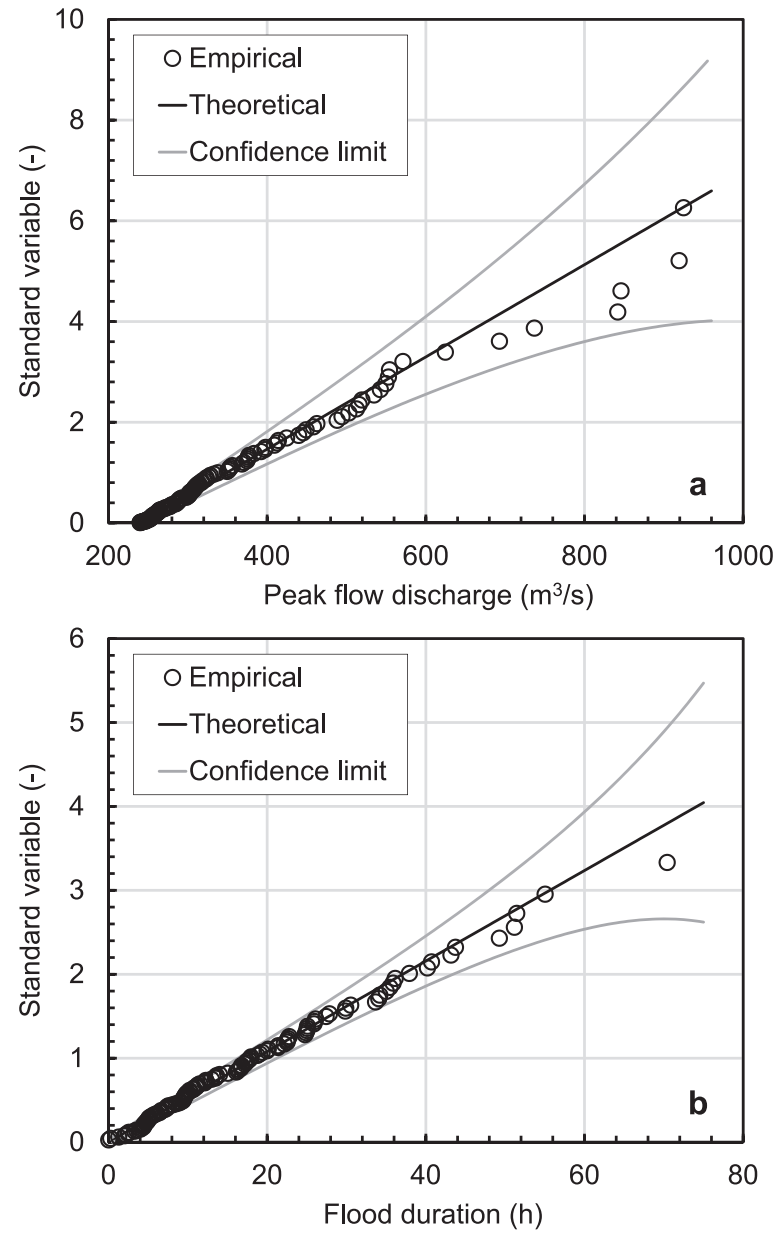

Fig. 3. Confidence boundary test of $a$ the peak flow discharge distribution and $b$ the flood duration distribution (10\% confidence limits).

Table 3

Kolmogorov-Smirnov statistics $D_{\max }$ and Anderson-Darling statistics $A^{2}$ and corresponding critical values $D_{n \alpha}$ and $A_{c}$ (10\% significance), obtained when testing the Weibull marginal distributions.

\begin{tabular}{lllll}
\hline Marginal distribution & $D_{\max }$ & $D_{n \alpha}$ & $A^{2}$ & $A_{c}$ \\
\hline Peak flow discharge & 0.048 & 0.112 & 0.367 & 0.637 \\
Flood duration & 0.046 & 0.112 & 0.364 & 0.637 \\
\hline
\end{tabular}

for corresponding statistical tables. As can be seen in Table 3, where test statistics are summarized along with the corresponding critical values for $10 \%$ significance, both null hypotheses cannot be rejected. Kolmogorov-Smirnov critical values were estimated with reference to large samples ( $n$ greater than 40), while Anderson-Darling statistics were increased by the correction factor $1+0.20 / n^{0.5}$, to account for that the distribution parameters are estimated from the sample used in the test. A satisfactory representation of the marginal tails by the Weibull functions is depicted for the peak flow discharge and the flood duration, as the Anderson-Darling statistics $A_{2}$ are less than the critical value $A_{c}$. Moreover, the goodness of the global adaptation is further confirmed by the Kolmogorov-Smirnov statistics $D_{\max }$, which is found to be significantly less than the critical value $D_{n \alpha}$.

\subsection{Residual hazard function derivation}

Two examples of the dichotomous split of the flood variable population derived by means of limit state function (5) are illustrated in Fig. 4,
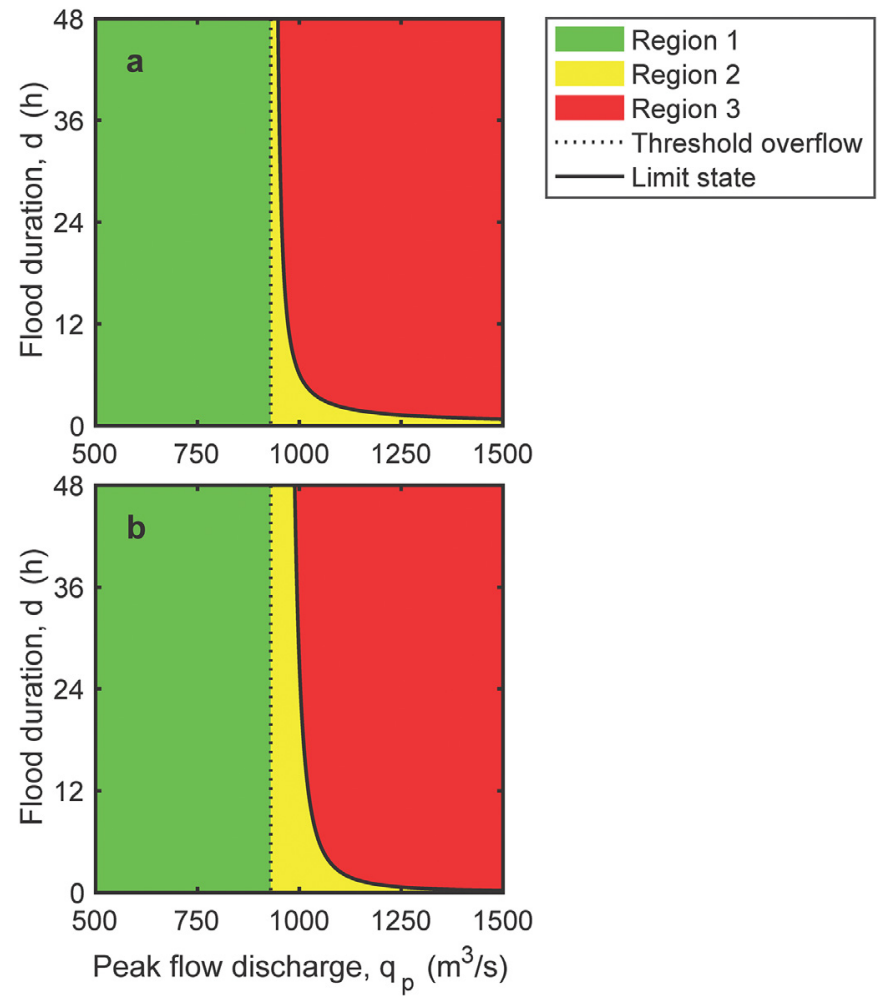

Fig. 4. Examples of the dichotomous split of the bivariate population induced by the limit state function for $q_{o}=930 \mathrm{~m}^{3} / \mathrm{s}, W_{o}=94 \mathrm{~m}, k_{s}=20 \mathrm{~m}^{1 / 3} / \mathrm{s}, \alpha=2.5$, and $a f_{g}=0.8$ and $b f_{g}=2.0$; failure region $\Lambda_{s}$ referred to the structural residual hazard (region 3), failure region $\Lambda_{d}$ referred to the design hydraulic residual hazard (union of region 3 and region 2), safety region referred to the structural residual hazard (union of region 1 and region 2), safety region referred to the design hydraulic residual hazard (region 1).

for two different turf cover resistances: common grass turf under poor condition Fig. 4a) and filled mats turf (Fig. 4b). In both cases, conceptually sound boundaries separating the safety region from the failure region are derived, as the peak flow discharge triggering the breaching mechanism due to overtopping decreases with the flood duration, asymptotically approaching the overflow threshold discharge $q_{o}$. Conversely, when short duration floods occur, very large peak flow discharges are needed for the overtopping breaching mechanism to be triggered. Further, region 2, including the flood events overtopping the levee crest but not triggering a breach, increases as the turf resistance strengthens. The failure region referred to the structural residual hazard $\Lambda_{s}$ defined in Eq. (11) is given by region 3, including flood events leading to negative values of the limit state function (5). Conversely, the union of region 1 and region 2, which are separated by the threshold overflow discharge $q_{o}$, is the complementary safety region. When the design hydraulic residual hazard is considered, the failure region $\Lambda_{d}$ defined in Eq. (13) is given by the union of region 2 and region 3, whereas the safety region is given by region 1 . Hence, the inequality relating $H_{N}$ to $H_{N}{ }_{N}$, discussed in Section 3.3, is respected, since the structural failure region $\Lambda_{s}$ is smaller than the design hydraulic failure region $\Lambda_{d}$.

Monte Carlo simulation outcomes are summarized in the box-plots reported in Fig. 5, where the variability due to the $H_{N}$ epistemic uncertainty, related to the four copula models listed in Table 1 , is estimated by analyzing $10^{3}$ simulation runs. The hazard variability in Fig. $5 \mathrm{a}$ is derived according to the JDF based on the Clayton copula, which is regarded in this study as a benchmark. The estimated average value of the annual probability of breaching due to overtopping is equal to $0.71 \%$, so that a return period of about 62 years can be associated to this kind of event. Such a result is consistent with the fact that breaches due to 

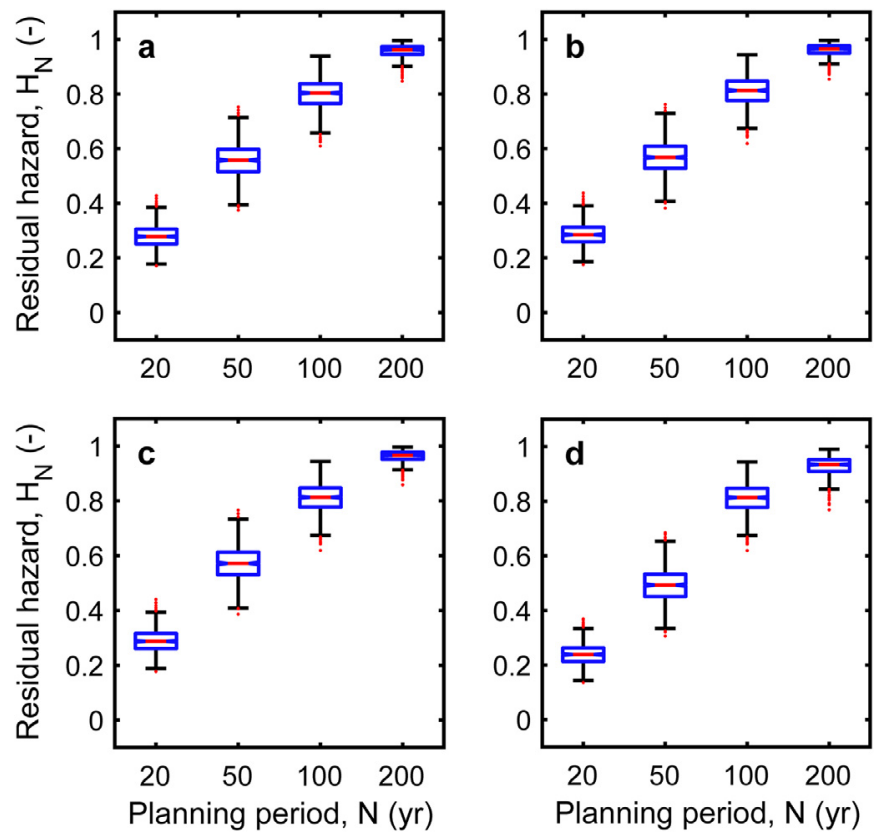

Fig. 5. Box plots of the structural residual hazard $H_{N}$ for different planning periods $N$, estimated through $a$ the Clayton copula, $b$ the $t$-Student copula, $c$ the Gumbel copula and $d$ the independence copula.

overtopping did not occur in this river section during the observation period of the flow discharges. However, the safety degree provided by this levee is largely insufficient. Indeed, the residual hazard $H_{N}$ is high. With reference to a time period $N$ of 100 years, conventionally adopted for the levee safety verification in the Po River hydrographic district, $H_{N}$ median is estimated to be $80 \%$, while, for $N$ equal to 200 years, $H_{N}$ rises up to $96 \%$. The epistemic uncertainty, assessed in the order of $\pm 5 \%$, for the time period of most interest (50-100 years), determines a moderate $H_{N}$ variability. Such a variability is found to decrease for the $N$ values of 20 years and 200 years, when $H_{N}$ approaches the lower and upper limits for the hazard.

When the box plots derived through the Clayton copula are compared to those derived through the $t$-Student copula, shown in Fig. $5 \mathrm{~b}$, and through the Gumbel copula, shown in Fig. 5c, almost identical estimates are found, both in terms of expected values and uncertainty. Acknowledging the existence of the upper tail dependence actually determines a slight $H_{N}$ overestimate, due to the increase in the copula density maxima in the failure region. The average values of annual breaching probability due to overtopping obtained by using the t-Student copula and the Gumbel copula are, respectively, 3\% and 4\% larger than those obtained from the Clayton copula. From a practical point of view, such overestimates are nevertheless negligible in terms of long-term hazard. On the contrary, the assumption of flood variable independence yields significant $H_{N}$ underestimates. The average value of the annual breaching probability due to overtopping is actually $16 \%$ less than the estimate obtained from the bivariate Clayton copula. Neglecting the dependence structure is often considered to be a conservative assumption, as assumed in the analytical-probabilistic methods when dealing with flow discharge derivations (Guo and Adams, 1999; Wang and Guo, 2018). In some applications it actually determines significant overestimates of the design hydrologic inputs (Balistrocchi and Bacchi, 2017). Herein, however, this result can easily be explained by the decrease in the copula density values in the failure region and its uniform redistribution in the safety region.

As shown in Fig. 6, where the box plots referred to the Clayton copula and to the independence copula are compared for different planning periods $N$, estimate differences are more appreciable than those due to the misinterpretation of the tail dependences, even though these differences
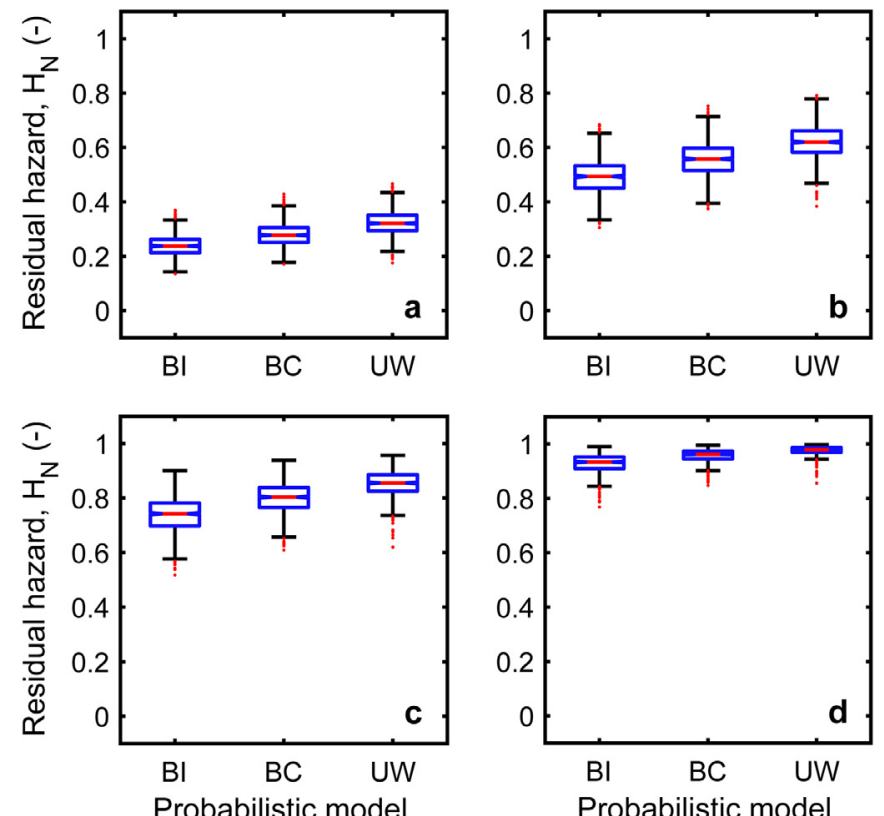

Fig. 6. Box plots of the structural residual hazard $H_{N}$, estimated through different models: bivariate model assuming the marginal variables independence (BI), bivariate model assuming the marginal variables dependence suiting the Clayton copula (BC), univariate model based on the Weibull distribution of the peak flow discharge (UW) (i.e. design hydraulic residual hazard); boxes are plotted for increasing planning periods $N$ : $a 20$ years, $b 50$ years, $c 100$ years and $d 200$ years.

can be assessed in no more than $5.0 \%$, for $N$ varying between 20 years and 100 years. When $N$ increases, such underestimate becomes negligible, as $H_{N}$ approaches the unity. In Fig. 6 an additional comparison is reported between the assessments of $H_{N}$ and $H^{\prime}{ }_{N}$. These last box plots derive from a univariate approach relying on CDF (3), where only the uncertainty of $q_{o}$ is accounted for. As can be seen, the residual hazard is greater than the ones assessed through the bivariate approaches. On the one hand, this outcome is meaningful and supports the reliability of the benchmark bivariate approach. On the other hand, the overestimate is acceptable in this kind of context. In terms of average values of the annual breaching probability due to overtopping, it amounts to $21.0 \%$, but in terms of long-term structural residual hazard it reduces down to $5.0 \%$, for the time periods of most interest. Therefore, the design hydraulic residual hazard could be considered an expeditious and conservative method to assess the structural residual hazard of breaching due to overtopping, when dealing with earthen levees conventionally protected by grass covers. This behavior is not characteristics of all the hazard assessment problems. For instance, Moftakhari et al. (2019), dealing with the hazard assessment in estuaries and tidal channels related to peak flow discharges and ocean levels, found that the OR method to estimate the return period is more conservative than the AND method, and both are more conservative than the univariate approaches only relying on marginals.

It is finally noted that the uncertainty estimated through the univariate approach shows to be moderately less than that estimated through the bivariate approach. In terms of variation coefficient of the annual breaching probability due to overtopping, the univariate approach features an epistemic uncertainty less than $4.4 \%$ with respect to the bivariate Clayton copula one. This demonstrates that, according to the failure mechanism methodology proposed in the present study, the major contribution to the overall epistemic uncertainty is related to overflow discharge. As expected, under the independence assumption, the epistemic uncertainty is broader, as the variation coefficient increases of $6.2 \%$ with respect to the bivariate Clayton copula assumption. 


\section{Summary and conclusions}

The bivariate probabilistic modeling of flood events has been used to develop a methodology for the estimation of the structural residual hazard, which can extensively be applied to earthen levees breaching due to overtopping (Section 3). This methodology delineates a conceptually sound and computationally efficient strategy to account for the multivariate nature of the earthen levee failure mechanisms triggered by floods. The mutual dependence of peak flow discharge and flood duration was suitably expressed by means of a Clayton copula, characterized by a strong concordance, a significant lower tail but a negligible upper tail (Table 2 and Fig. 2). The copula approach made it possible to effectively investigate the different factors affecting the specific failure mechanism considered in the present study (Section 5.1). This methodology was tested on a real-world levee lying along the Panaro River in northern Italy (Fig. 1). Results consistent with the historical knowledge and with the empirical data were obtained. The developed methodology is by no means site specific, as it can be exported to other earthen levee systems independently of the geographical area and the river flow regime.

A suitable representation of flow discharge, both in terms of marginal distributions and normal flow rating curve characterizing the analyzed river section, played a primary role in ensuring the overall reliability of the proposed methodology. This is due to the influence of the overflow threshold discharge in the split of the bivariate population into the safety region and the breach failure region (Section 5.2). The value of the peak flow discharge $q_{p}$ on the boundary separating such regions (solid line in Fig. 4) is greater than the overflow threshold value $q_{o}$ (dot line in Fig. 4) and tends to $q_{o}$ when the flood duration tends to infinity. Conversely, other aspects of the theoretical functions used to model the dependence structure, such as the upper tail dependence, have a nearly negligible impact on the residual hazard estimate (Fig. 5). This can be explained by the combination of some factors: the moderate capability of the other tested copulas to fit the sample data, the shape of the failure region, and the limit state function utilized to represent the particular failure mechanism modeled in the present study (Section 3). As discussed in Section 1, the existence of upper or lower tail dependence properties in flood event series is a long-debated argument in the literature, since its misinterpretation is often claimed as a reason for relevant hazard estimation errors. Focusing on modeling uncertainty, the low sensitivity to tails represents therefore an advantage of this methodology (Fig. 5ac).

An exception is nevertheless given by the independence copula (Fig. 5d): completely disregarding the concordance between peak flow discharge and flood duration leads to appreciable underestimates of the residual hazard, highlighting that the independence assumption is basically non-conservative and should therefore be avoided in the assessment of the hazard associated with breaching due to overtopping (Fig. 6). A more suitable assumption is obtained by equaling the overtopping probability to the breaching probability related to overtopping, herein referred to as design hydraulic residual hazard and structural residual hazard, respectively (Fig. 6). This evidence was found to be consistent with the real-world experience in the Po River valley, where breaches were normally observed when an earthen levee is overtopped by a barely significant overflow discharge. This outcome was easily be explained by the copula approach, as well (Section 5.2). Owing to the dependence structure delineated by the Clayton copula, the integral of copula density over the region included between the overflow threshold discharge and the boundary of the safety region was found to be small as compared to the failure probability (Fig. 4). This integral indeed measures the probability that an overtopping overflow does not trigger a breach (Section 3.3).

All these conclusions apply to conventional earthen levees, simply covered by grass or light brush, for which no specific protections are supplied in order to increase the erosion resistance capability of the levee crest and the inner talus. In presence of structural mitigation prac- tices, the limit state function herein considered should be extended, to account for different erosion mechanisms, so that significantly different results could be drawn. In this regard, future developments should involve the generalization of the bivariate approach presented in this study to alternative overtopping erosion dynamics or to different failure mechanisms, such as piping or seepage breaching. Indeed, the overall structural residual hazard must account for all the potential failure mechanisms. A further research perspective also includes the estimate of the flooding volume resulting from a breach triggered by a combination of peak flow discharge and flood duration pair and the resulting damages and residual risk.

\section{Declaration of Competing Interest}

The authors declare that they have no known competing financial interests or personal relationships that could have appeared to influence the work reported in this paper.

\section{Acknowledgments and data}

This research has been inspired by our colleague and friend Baldassare Bacchi, a true scholar in the field of water resources engineering and a gentleman, who passed away on November 16, 2018.

Hydrological data can be downloaded upon order from http://roberto-ranzi.unibs.it/home; hydrologic annexes, including the normal flow rating curve, are made available by ARPA Emilia Romagna https://www.arpae.it/sim/?idrologia/annali_idrologici. The Authors would like to thank the two anonymous reviewers for their valuable comments, which allowed them to significantly improve the paper.

\section{Supplementary material}

Supplementary material associated with this article can be found, in the online version, at doi:10.1016/j.advwatres.2019.103433.

\section{References}

Abberger, K., 2005. A simple graphical method to explore taildependence in stock-return pairs. Appl. Financ. Econ. 15 (1), 43-51. https://doi.org/10.1080/0960310042000280429.

Adams, B.J., Howard, C.D.D., 1986. Design storm pathology. Can. Water Resour. J. 11 (3), 49-55. https://doi.org/10.4296/cwrj1103049.

Akan, A.O., Houghtalen, R.J., 2003. Urban hydrology, Hydraulics and Stormwater Quality. John Wiley, Hoboken, NJ.

Angus, J.E., 1994. The probability integral transform and related results. SIAM Rev. 36 (4), 652-654. https://doi.org/10.1137/1036146.

Apel, H., Thieken, A.H., Merz, B., Blösch, G., 2004. Flood risk assessment and associated uncertainty. Nat. Hazard Earth Syst. Sci. 4 (2), 295-308. https://doi.org/10.5194/ nhess-4-295-2004.

Apel, H., Thieken, A.H., Merz, B., Blösch, G., 2006. A probabilistic modelling system for assessing flood risk. Nat. Hazards 38 (1-2), 79-100. https://doi.org/10.1007/ s11069-005-8603-7.

Apel, H., Merz, B., Thieken, A.H., 2009. Influence of dike breaches on flood frequency estimation. Comput. Geos. 35 (5), 907-923. https://doi.org/10.1016/ j.cageo.2007.11.003.

Aureli, F., Mignosa, P., 2004. Flooding scenarios due to levee breaking in the Po River. Proc. Inst. Civ. Eng. Water Manage. 157 (1), 3-12.

ARPAE (Agenzia Regionale per la Protezione Ambientale Emilia-Romagna), 2016. Hydrologic Annals, Part II https://www.arpae.it.

ASCE, 2014. Flood risk management: call for a national strategy. In: Traver, R. (Ed.), Task Committee on Flood Safety Policies and Practices of the American Society of Civil Engineers. ASCE, Restor, VG.

Balistrocchi, M., Bacchi, B., 2017. Derivation of flood frequency curves through a bivariate rainfall distribution based on copula functions: application to an urban catchment in Northern Italy's climate. Hydrol. Res. 48 (3), 749-762. https://doi.org/10.2166/nh.2017.109.

Balistrocchi, M., Orlandini, S., Ranzi, R., Bacchi, B., 2017. Copula-based modelling of flood control reservoir. Water Resour. Res. 53 (11), 9883-9900. https://doi.org/10.1002/ 2017WR021345.

Balistrocchi, M., Ranzi, R., Orlandini, S., Bacchi, B., 2018. Flood routing efficiency assessment: an approach using bivariate copulas. 13th International Hydroinformatics Conference. https://doi.org/10.29007/bjr1. 
Barbetta, S., Camici, S., Bertuccioli, P., Palladino, M.R., Moramarco, T., 2017. Levee body seepage: a refinement of an expeditious procedure for fragility curves and vulnerability diagrams' assessment. Hydrol. Res. 48 (3), 763-775. https://doi.org/10.2166/nh.2017.101.

Brunner, M.I., Viviroli, D., Sikorska, A.E., Vannier, O., Favre, A.-C., Seibert, J., 2017. Flood type specific construction of synthetic design hydrographs. Water Resour. Res. 53 (2), 1390-1406. https://doi.org/10.1002/2016WR019535.

Camici, S., Barbetta, S., Moramarco, T., 2017. Levee body vulnerability to seepage: the case study of the levee failure along the Foenna stream on 1 January 2006 (Central Italy). J. Flood Risk Manag. 10 (3), 314-325. https://doi.org/10.1111/jfr3.12137.

Castellarin, A., Di Baldassare, G., Brath, A., 2009. Floodplain management strategies for flood attenuation in the River Po. River Res. Appl. 27 (8), 1037-1047. https://doi.org/10.1002/rra.1405.

Chow, V.T., Maidment, D.R., Mays, L.W., 1988. Applied Hydrology. McGraw-Hill, Singapore, SG.

Chowdhary, H., Escobar, L.A., Singh, V.P., 2011. Identification of suitable copulas for bivariate frequency analysis of flood peak and flood volume data. Hydrol. Res. 42 (2-3), 193-216. https://doi.org/10.2166/nh.2011.065.

D’Agostino, R.B., Stephens, M.A., 1986. Goodness-of-Fit Techniques. Marcel Dekker, NY.

Dupuis, D.J., 2007. Using copulas in hydrology: benefits, cautions, and issues. J. Hydrol. Eng. 12 (4), 381-393. https://doi.org/10.1061/(ASCE)1084-0699(2007)12:4(381).

Eagleson, P., 1972. Dynamics of flood frequency. Water Resour. Res. 8 (9), 878-898. https://doi.org/10.1029/WR008i004p00878.

EU (European Union), 2007. Directive 2007/60/EC on the assessment and management of flood risks. Off. J. Eur. Union 227, 27-34.

Favre, A.-C., El Adlouni, S., Perreault, L., Thi'emonge, N., Bobée, B., 2004. Multivariate hydrological frequency analysis using copulas. Water Resour. Res. 40 (1), W01101. https://doi.org/10.1029/2003WR002456.

Fiorentini, M., Orlandini, S., 2013. Robust numerical solution of the reservoir routing equation. Adv. Water Resour. 59 (9), 123-132. https://doi.org/10.1016/ j.advwatres.2013.05.013.

Fisher, N.I., Switzer, P., 1985. Chi-plots for assessing dependence. Biometrika 72 (2), 253-265.

Fisher, N.I., Switzer, P., 2001. Graphical assessment of dependence: is a picture worth 100 tests? Am. Stat. 55 (3), 233-239. https://doi.org/10.1198/000313001317098248.

Fread, D.L., 1988. BREACH: An Erosion Model for Earthen Dam Failures. Silver Spring, MD US National Weather Service Report, 35.

Ganguli, P., Reddy, M.J., 2013. Probabilistic assessment of flood risks using trivariate copulas. Theor. Appl. Climatol. 111 (1-2), 341-360. https://doi.org/10.1007/ s00704-012-0664-4.

Genest, C., Favre, A., 2007. Everything you always wanted to know about copula modeling but were afraid to ask. J. Hydrol. Eng. 12 (4), 347-368. https://doi.org/10.1061/ (ASCE)1084-0699(2007)12:4(347).

Genest, C., Rémillard, B., Beaudoin, D., 2009. Goodness-of-fit tests for copulas: a review and a power study. Insur. Math. Econ. 44 (2), 199-213. https://doi.org/10.1016/ j.insmatheco.2007.10.005.

Grimaldi, S., Serinaldi, F., 2006. Asymmetric copula in multivariate flood frequency analysis. Adv. Water Resour. 29 (8), 1115-1167. https://doi.org/10.1016/ j.advwatres.2005.09.005.

Guo, Y., Adams, B.J., 1999. An analytical probabilistic approach to sizing flood control detention facilities. Water Resour. Res. 35 (8), 2457-2468. https://doi.org/10.1029/ 1999 WR900125.

Han, K.-Y., Lee, J.-T., Park, J.-H., 1998. Flood inundation analysis resulting from levee-break. J. Hydraul. Res. 36 (5), 747-759. https://doi.org/10.1080/ 00221689809498600 .

Hesselink, A.W., Stelling, G.S., Kwadijk, J.C.J., Middelkoop, H., 2003. Inundation of a Dutch river polder, sensitivity analysis of a physically based inundation model using historic data. Water Resour. Res. 39 (9), SWC11-SWC117. https://doi.org/10.1029/2002WR001334.

Hewett, H., Boorman, L., Bramley, M., 1987. Design of Reinforced Grass Waterways. Construction Industry Research and Information Association, London, UK.

Hofert, M., Kojadinovic, I., Mächler, M., Yan, J., 2018. Elements of Copula Modeling With R. Springer, Switzerland

Karmakar, S., Simonovic, S.P., 2009. Bivariate flood frequency analysis part 2: a copulabased approach with mixed marginal distributions. J. Flood Risk Manag. 2 (1), 32-44. https://doi.org/10.1111/j.1753-318X.2009.01020.x.

Kates, R.W., Colten, C.E., Laska, S., Leatherman, S.P., 2006. Reconstruction of New Orleans after Hurricane Katrina: a research perspective. PNAS 103 (40), 14653-14660. https://doi.org/10.1073/pnas.0605726103.

Kellens, W., Vanneuville, W., Verfaille, E., Meire, E., Deckers, P., De Mayer, P., 2013. Flood risk management in Flanders: past developments and future challenges. Water Resour. Manage. 27 (10), 3585-3606. https://doi.org/10.1007/s11269-013-0366-4.

Kottegoda, N.T., Rosso, R., 2008. Applied Statistics For Civil and Environmental Engineers. Blackwell Publishing, Oxford, UK.

Joe, H., 1997. Multivariate Models and Dependence Concepts. Chapman \& Hall, London, UK.

Lang, M., Ouarda, T.B.M.J., Bobée, B., 1999. Towards operational guidelines for over-threshold modeling. J. Hydrol. 225 (3-4), 103-117. https://doi.org/10.1016/ S0022-1694(99)00167-5.

Ludy, J., Kondolf, G., 2012. Flood risk perception in lands 'protected' by 100 -year levees. Nat. Hazards 61 (2), 829-842. https://doi.org/10.1007/s11069-011-0072-6.

Mai, J.-F., Scherer, M., 2012. Simulating copulas. Vol. 4 of Series in Quantitative Finance. Imperial College Press, London UK.

Majone, U., Mignosa, P., Tomirotti, M., 2003. Regional estimation of synthetic design hydrographs. Intl. J. River Basin Manag. 1 (2), 151-163. https://doi.org/10.1080/ 15715124.2003.9635202.
Mazzoleni, M., Bacchi, B., Barontini, S., Di Baldassare, G., Pilotti, M., Ranzi, R., 2014. Flooding hazard mapping in floodplain areas affected by piping breaches in the Po River, Italy. J. Hydrol. Eng. 19 (4), 717-731. https://doi.org/10.1061/ (ASCE)HE.1943-5584.0000840.

Mazzoleni, M., Dottori, F., Brandimarte, L., Shewandagn, T., Martina, M.L.V., 2017. Effects of levee cover strength on flood mapping in the case of levee breach due to overtopping. Hydrolog. Sci. J. 62 (6), 892-910. https://doi.org/10.1080/ 02626667.2016.1246800.

Michelazzo, G., Paris, E., Solari, L., 2018. On the vulnerability of river levees induced by seepage. J. Flood Risk Manag. 11 (S2), S677-S686. https://doi.org/10.1111/ jfr3.12261.

Milanesi, L., Pilotti, M., Ranzi, R., 2015. A conceptual model of people's vulnerability to floods. Water Resour. Res. 51 (1), 182-197. https://doi.org/10.1002/ 2014WR016172.

Moftakhari, H., Schubert, J.E., AghaKouchak, A., Matthew, R.A., Sanders, B.F., 2019. Linking statistical and hydrodynamic modeling for compound flood hazard assessment in tidal channels and estuaries. Adv. Water Res. 128, 28-38. https://doi.org/10.1016/j.advwatres.2019.04.009.

NCHRP (National Cooperative Highway Research Program), 2016. Minimizing Roadway Embankment Damage from Flooding: A Synthesis of Highway Practice. Transportation Research Board, Washington, DC.

Nelsen, R.B., 2006. An Introduction to Copulas, second ed. Springer, New York, NY.

Orlandini, S., Moretti, G., Albertson, J.D., 2015. Evidence of an emerging levee failure mechanism causing disastrous floods in Italy. Water Resour. Res. 51 (10), 7995-8011. https://doi.org/10.1002/2015WR017426.

Poulin, A., Huard, D., Favre, A.C., Pugin, S., 2007. Importance of tail dependence in bivariate frequency analysis. J. Hydrol. Eng. 12 (4), 394-403. https://doi.org/10.1061/ (ASCE)1084-0699(2007)12:4(394).

Ranzi, R., 2005. Structural and non-structural methods for flood hazard mitigation. Workshop on Natural Environment, Sustainable Protection and Conservation: Italy-Vietnam Cooperation Perspectives.

Ranzi, R., Bacchi, B., Barontini, S., Ferri, M., Mazzoleni, M., 2013. Levee breaches statistics, "geotechnical uncertainty", residual risk in flood hazard mapping. 35th IAHR World Congress, "The wise find pleasure in water: meandering through science and engineering", September 8-13.

Requena, A.I., Mediero, L., Garrote, L., 2013. A bivariate return period based on copulas for hydrologic dam design: accounting for reservoir routing in risk estimation. Hydrol. Earth Syst. Sci. 17 (8), 3023-3038. https://doi.org/10.5194/hess-17-3023-2013.

Salvadori, G., De Michele, C., 2004. Frequency analysis via copulas: theoretical aspects and applications to hydrological events. Water Resour. Res. 40, W12511. https://doi.org/10.1029/2004WR003133.

Salvadori, G., De Michele, C., Kottegoda, N.T., Rosso, R., 2007. Extremes in nature: an Approach Using Copulas. Springer, Dordrecht, NL.

Salvadori, G., De Michele, C., 2006. Statistical characterization of temporal structure of storms. Adv. Water Resour. 29 (6), 827-842. https://doi.org/10.1016/ j.advwatres.2005.07.013.

Salvadori, G., Durante, F., Tomasicchio, G.R., D’Alessandro, F., 2015. Practical guidelines for the multivariate assessment of the structural risk in coastal and off-shore engineering. Coast. Eng. 95, 77-83. https://doi.org/10.1016/j.coastaleng.2014.09.007.

Salvadori, G., Durante, F., De Michele, C., Bernardi, M., Petrella, L., 2016. A multivariate copula-based framework for dealing with hazard scenarios and failure probabilities. Water Resour. Res. 52 (5), 3701-3721. https://doi.org/10.1002/2015WR017225.

Schumann, A., 2017. Flood safety versus remaining risks - options and limitations of probabilistic concepts in flood management. Water Resour. Manag. 31 (10), 3131-3145. https://doi.org/10.1007/s11269-017-1700-z.

Serinaldi, F., 2015. Dismissing return period!. Stoch. Env. Res. Risk. A 29 (4), 1179-1189.

Serinaldi, F., Bardossy, A., Kilsby, C.G., 2015. Upper tail dependence in rainfall extremes: would we know it if we saw it? Stoch. Env. Res. Risk A 29 (4), 1211-1233. https://doi.org/10.1007/s00477-014-0946-8.

Sklar, A., 1959. Fonctions de répartition à n dimensions et leures marges. Publ. Inst. Statist. Univ. Paris 8, 229-231.

SII (Servizio Idrografico Italiano), 1940. Hydrologic Annexes, Part II. Istituto Poligrafico dello Stato, Rome, IT (in Italian).

Thomas, H.A., 1948. Frequency of minor floods. J. Boston Soc. Civ. Eng. 35 (1), 425-442.

Todorovic, P., 1978. Stochastic models of floods. Water Resour. Res. 14 (2), 345-356. https://doi.org/10.1029/WR014i002p00345.

UNISDR (United Nations International Strategy for Disaster Reduction), 2009. 2009 UNISDR Terminology on Disaster Risk Reduction. UNISDR, Geneva, CH.

USACE (United States Army Corps of Engineers), 1996. Risk-Based Analysis for Flood Damage Reduction Studies. USACE, Washington DC, USA Engineer Manual 1110-2-1619.

USACE (United States Army Corps of Engineers), 1999. Risk-Based Analysis in Geotechnical Engineering for Support of Planning Studies. USACE, Washington DC, USA Engineer technical letter 1110-2-556.

Varnes, D.J.IAEG (International Association for Engineering Geology), 1984. Landslide Hazard Zonation: A Review of Principle and Practice. UNESCO, Paris, FR.

Volpi, E., Fiori, A., 2014. Hydraulic structures subject to bivariate hydrological loads: return period, design, and risk assessment. Water Resour. Res. 50 (2), 885-897. https://doi.org/10.1002/2013WR014214.

Vorogushyn, S., Merz, B., Apel, H., 2009. Development of dike fragility curves for piping and micro-instability breach mechanisms. Nat. Hazard Earth Syst. Sci. 9 (4), 13831401. https://doi.org/10.5194/nhess-9-1383-2009.

Vrijling, J.K., 2000. Probabilistic Design. Institute of Hydraulic Engineering, Delft, NL Lecture notes.

Vrijling, J.K., 2001. Probabilistic design of water defense systems in the Netherlands. Reliab. Eng. Syst. Safe. 74 (3), 337-344. https://doi.org/10.1016/S09518320(01)00082-5. 
Wang, J., Guo, Y., 2018. An analytical stochastic approach for evaluating the performance of combined sewer overflow tanks. Water Resour. Res. 54 (5), 3357-3375. https://doi.org/10.1029/2017WR022286.

Wilby, R., Beven, K., Reynard, N., 2008. Climate change and fluvial flood risk in the UK: more of the same? Hydrolog. Process. 22 (14), 2511-2523. https://doi.org/10.1002/ hyp.6847.
Yevjevich, V., 1967. An Objective Approach to Definitions and Investigations of Continental Hydrologic Droughts. Colorado State University, Fort Collins, Colorado Hydrological Papers 23.

Zhang, L., Singh, V.P., 2007. Trivariate flood frequency analysis using the GumbelHougaard copula. J. Hydrol. Eng. 12 (4), 431-439. https://doi.org/10.1061/ (ASCE)1084-0699(2007)12:4(431). 